FACING TOMORROW'S CHALLENGES: USGS SCIENCE IN THE DECADE 2007-2017

\title{
The Role of Environment and Wildlife in Human Health
}

In 2007, the U.S. Geological Survey (USGS) developed a science strategy outlining the major natural science issues facing the Nation in the next decade. The science strategy consists of six science directions of critical importance, focusing on areas where natural science can make a substantial contribution to the well-being of the Nation and the world. This fact sheet focuses on the role of environment and wildlife in human health and how USGS research can strengthen the Nation with information needed to meet the challenges of the 21 st century.

\section{Importance of Research on Environment/Wildlife/Human- Health Interactions}

Environmental health threats to the Nation's citizens are an inescapable consequence of the interactions between people and their physical, chemical, and biological environment. As towns and cities expand, the wildland-urban interface broadens and human-wildlife interactions are increasingly frequent. The emergence of many new human diseases in recent years is directly related to worldwide increases in population density, mobility, and environmental disruption. Many public health issues affecting Americans, such as avian influenza ("bird flu"), originate outside our borders, requiring the Nation to maintain global vigilance for potential health threats. Major health threats also arise from naturally occurring toxicants and anthropogenically derived environmental contaminants. Such contaminants are increasingly appearing in natural ecosystems. Some of these contaminants are bioaccumulative; they persist in the environment and accumulate in living organisms and tend to increase up the food chain. The health consequences of chronic exposure of low levels of these substances are commonly unknown but potentially important.

\section{Why Action Is Needed Now}

The current (2007) health problems caused by zoonotic diseases (that is, those transmissible between animals and humans, such as West Nile virus and avian influenza) and environmental contamination (for example, mercury in fish, arsenic in water, naturally present asbestos) are not isolated examples. Future generations will continue to be affected by many of the diseases that have emerged or resurged during the past quarter-century, regardless of whether the causes are chemical, microbial, or parasitic. Dealing with emerging and resurging diseases requires the ability to anticipate potential environmental and ecosystem health threats, recognize pathogens or contaminants when they first appear, and respond quickly and appropriately.

Environmentally related diseases inevitably will increase as the isolation previously provided by walls of geographic distance are removed and the opportunity for the spread of once isolated diseases increases. Public health risks will further intensify as population growth continues, bringing with it associated pressures of development, resource use, and habitat modification. Chemical and microbial contaminants will increasingly affect the quality of water, air, and consumables.

\section{Bird Deaths from West Nile Virus}

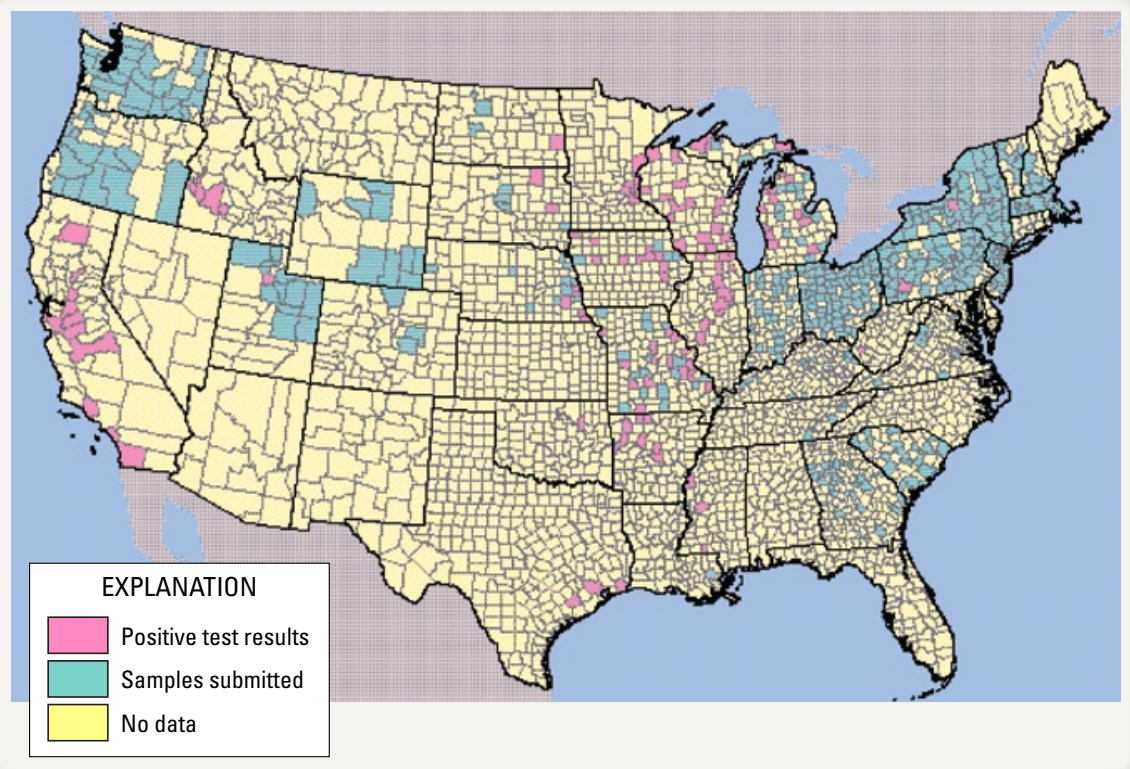

Bird deaths from West Nile virus infections January 1 to July 11, 2006. Birds are sentinels of human exposure to this virus, which is transferred to people by mosquitoes. The national dead-bird infection data can be translated into an epidemiological tool by adding information on climate, land use, and human demographics that are related to incidence, prevalence, and persistence in human exposure to existing mosquito populations. 


\section{How the USGS Can Help}

As the only integrated natural resources research bureau in the Federal Government, USGS is the primary governmental agency responsible for monitoring wildlife (Migratory Bird Treaty Act of 1918) and is at the forefront of identifying wild animal disease reservoirs. With this expertise, USGS science complements and can augment public health decisionmaking in America. In addition, USGS serves as an unbiased translator of environmental information to help address public health needs. USGS scientists have a national scope and transdisciplinary approach to addressing environmental aspects of human health issues and are among the world's experts on wild animal disease transmission to humans, drinking-water contaminants, air-dust-soil-sediment-rock contaminants, pathogens in recreational water, and the use of wild animals as sentinels of human health (see http://health. usgs.gov/). The position of USGS as a nonregulatory agency, with capabilities in environmental monitoring and mapping at all scales from national to local, and the ability to understand environ-

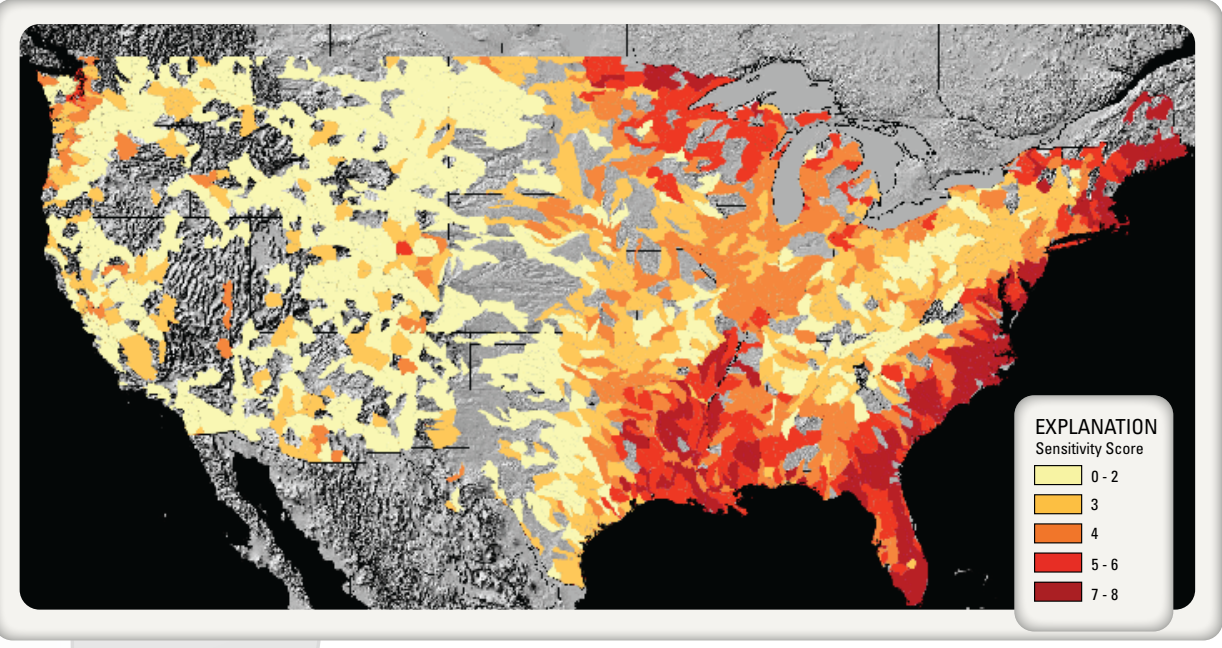

Mercury vulnerability map for aquatic ecosystems in the contiguous $\mathbf{4 8}$ States-Mercury in fish is the primary route of exposure for people and fish-eating wildlife. The mercury vulnerability map above shows areas where production of methylmercury (the most toxic form of mercury) is most likely to take place if inorganic mercury is present. The map is based on USGS water-chemistry data from more than 55,000 sites and 2,500 watersheds; higher values indicate greater vulnerability. mental and ecological processes, is found nowhere else in the Federal Government. Thus, the USGS is uniquely qualified to provide the information needed to link environmental and human health issues. To use this expertise in support of the Nation's health needs, the USGS will

\section{USGS Science Can Meet the Challenge}

\section{The USGS is ready to take action by:}

- Developing an online data atlas of potential environmental health threats that consolidates USGS data and information and provides data for researchers and public-health agencies to enhance the Nation's ability to respond quickly to current threats and anticipate potential future zoonotic and contaminant health threats.

- Creating new partnerships, strengthening existing partnerships, and enhancing collaboration with other entities charged with responsibility for environmental and public health. Increased levels of collaboration at all levels are needed to address the Nation's environmental health-related issues.

- Enhancing rapid and long-term response teams to evaluate short- and long-term health implications of disasters; identifying and assessing the changing patterns and root environmental factors related to chronic and emerging diseases.

- Developing and implementing a national-scale, environmental health information system that combines biological, water-quality, and geologic information with GIS decision-support tools.

- Publishing a report every half decade that includes the status and trends in environmental, animal, and earth science information. The report will describe the way conditions are changing, present new findings relating to public health, and explain the methodological and research contributions that USGS has made and transferred to management of soil, vegetation, freshwater, and oceans. fully integrate its massive data holdings and produce a national database and atlas of geology- and ecology-sourced diseases and toxicants. Once this atlas is in place, the USGS will partner with allied health science agencies to support spatially related health issues.

\section{A Vision For the Future}

The USGS works with health agencies to develop and maintain an international database and atlas of wildlife- and geology-sourced diseases and toxicants and a nationalscale environmental health information system. Improved strategies to mitigate diseases and toxicants are based on USGS research to identify and understand pathways through which toxicants and animal-borne diseases migrate in the environment and the processes by which they are transferred to people from environ-

\section{For Additional Information}

U.S. Geological Survey, 2007, Facing Tomorrow's Challenges-U.S. Geological Survey Science in the Decade 2007-2017: Available online at $h t t p: / /$ pubs.er.usgs.gov/usgspubs/cir/cir1309

Also, visit the USGS home page at http://www.usgs.gov/ mental sources. 